\title{
Concretos refratários preparados com alumina hidratável: efeito dos dispersantes
}

\author{
(Refractory castables prepared with hydratable alumina: \\ the dispersant effect)
}

\author{
I. R. Oliveira, V.C. Pandolfelli \\ Departamento de Engenharia de Materiais - DEMa, Universidade Federal de S. Carlos - UFSCar \\ Rod. Washington Luiz, km 235, C.P. 676, S. Carlos, SP 13565-905 \\ ivone@iris.ufscar.br,vicpando@power.ufscar.br
}

\begin{abstract}
Resumo
Uma alumina de transição capaz de formar fases hidratadas em água tem sido utilizada como ligante hidráulico alternativo para concretos refratários. Entretanto, têm-se observado que a secagem de concretos preparados com este ligante é normalmente mais lenta do que no caso de composições contendo cimento. Essa característica pode favorecer a pressurização do vapor de água gerado no interior do concreto durante a secagem, podendo culminar na explosão do revestimento refratário. O presente trabalho teve como objetivo relacionar o tipo de aditivo utilizado no processamento de concretos refratários com seu comportamento de secagem e resistência mecânica, por meio da atuação do aditivo na dispersão da matriz do concreto e no mecanismo de hidratação do ligante. Embora a dispersão das partículas do ligante mostre-se primordial no desenvolvimento das fases hidratadas, o total recobrimento da superfície das partículas pelo aditivo ácido cítrico desfavoreceu a hidratação gerando defeitos nos corpos e comprometendo a sua aplicação. Por outro lado, os aditivos poliméricos foram apontados como os mais efetivos para conciliar dispersão e desenvolvimento de fases hidratadas com conseqüente ganho de resistência mecânica.

Palavras-chave: concretos refratários, dispersantes, secagem, alumina hidratável.
\end{abstract}

\begin{abstract}
A reactive alumina able of forming hydrated phases in water has been used as an alternative hydraulic binder in refractory castables. However, it has been observed that the drying of these materials is usually slower comparing to cement containing compositions. Due to reduction of the permeability, this aspect increases the difficult of the vapor migration and can promote water vapor pressurization inside the structure and, eventually, explosion of refractories. Additives usually used in refractory castables, in order to promote matrix dispersion, are shown to affect the hydratable alumina hydration mechanism. The dispersion of binder particles presents a main role in the development of hydratable phases but the coating of the particles surfaces by the additive inhibits the hydration. Comb-like chain additives were indicated in order to match dispersion and hydration of castables containing hydratable alumina as a binder.
\end{abstract}

Keywords: Refractory castables, dispersants, drying, mechanical strength, hydratable alumina.

\section{INTRODUÇÃO}

A indústria de refratários tem dedicado esforços na busca de concretos que permitam alta taxa de secagem [1, 2]. A secagem e o aquecimento inicial são etapas críticas do processo de instalação de concretos refratários [3]. Por se tratarem de materiais densos e de baixa permeabilidade, a remoção da água utilizada na mistura e para hidratação do ligante deve ser feita de forma cuidadosa, de modo a evitar a pressurização da estrutura pelo vapor de água formado. Se os níveis de pressão atingirem o limite de resistência mecânica do concreto, danos estruturais como trincas e explosões podem ocorrer [3]. Por outro lado, a utilização de programas de secagem muito lentos torna o processo oneroso pela energia extra que consome e pelo tempo ocioso dos equipamentos de produção.
Uma alumina reativa capaz de formar fases hidratadas em água e que não contém $\mathrm{CaO}$ em sua composição tem sido utilizada como ligante hidráulico alternativo para concretos refratários [4, 5]. Tais ligantes hidráulicos podem ser compostos por uma variedade de fases de transição da alumina. São geralmente produzidos pela calcinação rápida da gibsita, resultando principalmente na alumina-rho $(\rho)$, que apresenta baixa cristalinidade e alta área superficial. A capacidade ligante deste material deriva da sua fácil rehidratação quando em contato com a água a temperatura ambiente [6]:

$\rho-\mathrm{Al}_{2} \mathrm{O}_{3}+\mathrm{H}_{2} \mathrm{O} \rightarrow \mathrm{Al}_{2} \mathrm{O}_{3} \cdot 3 \mathrm{H}_{2} \mathrm{O}+\mathrm{Al}_{2} \mathrm{O}_{3}(1 \approx 2) \mathrm{H}_{2} \mathrm{O}$

Todavia, têm-se observado que a secagem de concretos preparados com esta alumina é normalmente mais lenta 
do que no caso de composições contendo cimento. Essa característica pode favorecer a pressurização do vapor de água gerado no interior do concreto durante a secagem, podendo culminar na explosão do revestimento refratário. A formação de gel a partir do seu processo de hidratação também provoca uma diminuição na permeabilidade do material dificultando o processo de secagem $[4,5]$.

Tal processo de hidratação envolve, nos primeiros estágios da hidratação, a formação de uma espessa camada de alumina gel e, com o decorrer da reação, parte deste gel é transformado em boemita $\left(\mathrm{Al}_{2} \mathrm{O}_{3} 1 \approx 2 \mathrm{H}_{2} \mathrm{O}\right)$ e principalmente baierita $\left(\mathrm{Al}_{2} \mathrm{O}_{3} 3 \mathrm{H}_{2} \mathrm{O}\right)$. Os cristais interligados de baierita e o gel conferem resistência mecânica a verde aos refratários por meio do preenchimento de poros e redução dos defeitos superficiais [4].

O processo de hidratação da alumina hidratável, assim como ocorre para cimentos de aluminato de cálcio [7, 8], pode ser significativamente modificado em função da presença de diferentes tipos de aditivos orgânicos e inorgânicos. A função principal de aditivos em concretos é a dispersão das partículas da matriz visando a obtenção de altos valores de fluidez, acarretando no decréscimo do consumo de água e em boa trabalhabilidade. Entretanto, os aditivos também influenciam a hidratação da alumina hidratável frequientemente retardando ou acelerando as reações. Em baixa temperatura a reação pode ser efetivamente acelerada na presença de aditivos que promovem a formação de baierita como é o caso de sais de metal alcalino. Por outro lado, a formação de baierita é inibida na presença de ácido carboxílico resultando na formação de boemita gel [4].

Neste contexto, o presente trabalho teve como objetivo relacionar o tipo de aditivo utilizado no processamento de concretos refratários com seu comportamento de secagem e resistência mecânica, por meio da atuação do aditivo na dispersão do concreto e no mecanismo de hidratação do ligante.

\section{MATERIAIS E MÉTODOS}

Os concretos refratários foram formulados segundo o modelo de empacotamento de partículas de Andreasen [9], com coeficiente (q) 0,21, com o software PSDesigner [10]. Aluminas eletrofundidas brancas com variação de tamanho de partículas na faixa de 4750 - $11 \mu \mathrm{m}$ foram usadas como agregado (75\%-p), enquanto a matriz constituiu-se das aluminas calcinadas A 17NE (14\%-p) e CT3000SG (5\%p). Como agente ligante foi utilizada a alumina hidratável Alphabond 300 da Almatis-US (6\%-p). Os aditivos dispersantes avaliados foram: ácido cítrico anidro (Labsynth, $192 \mathrm{~g} / \mathrm{mol}, 99,5 \%$ pureza) e os polímeros da família do poliglicol, fornecidos pela Bayer-Alemanha (CD e CS). Os teores de aditivos e de água necessários para a preparação de cada composição foram previamente determinados [11] e são apresentados na Tabela I.

A mistura das matérias-primas, após pesagem das composições formuladas, foi realizada em um reômetro para concretos [12] com rotação constante de 44 rpm.
Tabela I - Teores de aditivos e de água determinados para a preparação das diferentes composições dos concretos refratários.

[Table I - Additive and water content for preparing the different compositions of refractory castables.]

\begin{tabular}{ccccc}
\hline Composição & $\begin{array}{c}\text { Tipo de } \\
\text { dispersante }\end{array}$ & $\begin{array}{c}\text { Teor de } \\
\text { dispersante } \\
(\%-p)\end{array}$ & $\begin{array}{c}\text { Teor de } \\
\text { água } \\
(\%-p)\end{array}$ & $\begin{array}{c}\text { Fluidez } \\
\text { livre } \\
(\%)\end{array}$ \\
\hline \multirow{5}{*}{ Alphabond } & $\begin{array}{c}\text { Sem } \\
\text { dispersante }\end{array}$ & - & 5,5 & 0 \\
& $\begin{array}{c}\text { Ácido } \\
\text { cítrico }\end{array}$ & 0,21 & 6,0 & 74 \\
& CD & 0,21 & 5,5 & 80 \\
& CS & 0,21 & 5,5 & 74 \\
\hline
\end{tabular}

A adição do teor de água definido para cada tipo de composição foi realizada em etapas para garantir a efetiva mistura dos sistemas otimizando a fluidez [13]. Após mistura a seco, por $60 \mathrm{~s}$, visando a quebra de aglomerados e conseqüente homogeneização de seus componentes, adicionou-se $75 \%$ do total de água necessária para a "virada do concreto", a qual pode ser definida como o momento no qual o concreto passa a se comportar como um meio contínuo. Ao alcançar o ponto de virada, o restante da água foi adicionado e a rotação foi mantida até a completa mistura do sistema.

Em seguida, os concretos foram moldados utilizando-se moldes de PVC cilíndricos $(\mathrm{h}=\mathrm{d}=40 \mathrm{~mm})$ aos quais foi aplicada uma fina camada de desmoldante. Posteriormente, tais amostras foram curadas na temperatura de $50{ }^{\circ} \mathrm{C}$ numa câmara climatizada Vötsch 2020, em ambiente insaturado (ao ar) durante 24 e $168 \mathrm{~h}$.

Após os tempos definidos de cura, as amostras de concretos com as diferentes composições foram caracterizadas quanto à resistência mecânica e perfil de secagem. Ensaios quanto à porosidade aparente também foram realizados para composições preparadas na presença dos aditivos ácido cítrico e CS.

Os ensaios de resistência mecânica por compressão diametral (ASTM C 496-90) foram realizados em amostras secas $50{ }^{\circ} \mathrm{C}$ (imediatamente após a cura) ou a $110{ }^{\circ} \mathrm{C}$ durante 3 dias, utilizando-se uma máquina de ensaios universal MTS 810 a uma taxa de aplicação de carga de 42 N/s. A tensão de ruptura foi calculada a partir da equação abaixo:

$$
\sigma_{R}=2 \cdot\left(\frac{P_{\text {max }}}{\pi \cdot L \cdot D}\right)
$$

onde: $\sigma_{\mathrm{R}}$ é a tensão de ruptura (MPA); $\mathrm{P}_{\max }$ é a força de ruptura (N); L é a altura (m) e D o diâmetro da amostra (m).

Os ensaios de secagem foram realizados em amostras secas a $50{ }^{\circ} \mathrm{C}$. Amostras preparadas a partir de suspensões aquosas de Alphabond 300 na presença dos aditivos ácido cítrico e CS, curadas durante 24, 72 e 168 h em ambiente 
insaturado a $50{ }^{\circ} \mathrm{C}$, também foram submetidas a ensaios de secagem.

O equipamento utilizado consiste de uma balança eletrônica acoplada a um forno elétrico. Foram coletadas simultaneamente a perda de massa da amostra e a temperatura do forno em função do tempo de ensaio. Em todos os ensaios também foram analisadas amostras contendo um termopar para a coleta simultânea da temperatura na superfície da amostra. $\mathrm{O}$ aquecimento foi efetuado à $2,5^{\circ} \mathrm{C} / \mathrm{min}(30-800$ ${ }^{\circ} \mathrm{C}$ ), com patamar de $20 \mathrm{~min}$ em $800{ }^{\circ} \mathrm{C}$. O mecanismo de consolidação de concretos ligados por Alphabond 300, devido à formação de um gel que causa reduções significativas na porosidade e permeabilidade, gera estruturas compactas $[4,6]$. Por isso, a etapa de secagem dessas composições é dificultada, podendo gerar trincas e explosões. Assim, foi aplicada uma taxa de aquecimento baixa.

A perda de massa, avaliada pelo parâmetro $\mathrm{W}$ e sua derivada em relação ao tempo (taxa de secagem) são definidas respectivamente nas equações:

$$
\begin{aligned}
& \mathrm{W}(\%)=100 \times\left(\frac{\left(\mathrm{M}_{\mathrm{o}}-\mathrm{M}\right)}{\left(\mathrm{M}_{\mathrm{o}}-\mathrm{M}_{\mathrm{f}}\right)}\right) \\
& \mathrm{dW} / \mathrm{dt}(\% / \mathrm{min})=\mathrm{d} / \mathrm{dt}\left(\frac{\left(\mathrm{M}_{\mathrm{o}}-\mathrm{M}\right)}{\left(\mathrm{M}_{\mathrm{o}}-\mathrm{M}_{\mathrm{f}}\right)}\right)
\end{aligned}
$$

onde, $\mathrm{W}$ indica a perda de água que ocorre durante o aquecimento em relação a massa final de concreto seco; $\mathrm{M}$ é a massa instantânea medida no tempo $t_{i}, M_{o}$ a massa inicial e $\mathrm{M}_{\mathrm{f}}$ a massa final.

A porosidade aparente dos concretos foi obtida pelo método de imersão de Archimedes, utilizando querosene como líquido de imersão (norma ASTM C830). O ensaio foi realizado para corpos de provas curados durante 24 e $168 \mathrm{~h}$ e secos a $110^{\circ} \mathrm{C}$ durante 3 dias.

\section{RESULTADOS E DISCUSSÃO}

Quando avaliada a capacidade de dispersão do concreto (matriz e ligante) por meio de medidas de fluidez [11] na presença dos aditivos ácido cítrico, CD e CS foi observado que o ácido cítrico mostrou-se o menos eficiente (Tabela I) uma vez que para a obtenção de uma fluidez próxima a dos demais aditivos foi consumido um maior teor de água.

Além disso, a hidratação do Alphabond 300 é sensivelmente inibida na presença de ácido cítrico. $O$ mecanismo de bloqueio da hidratação das partículas de alumina hidratável devido à adsorção das moléculas desse aditivo caracteriza a sua ação retardadora. Por se tratar de moléculas pequenas deve recobrir mais eficientemente as superfícies quando comparado a adsorção dos demais aditivos. O tempo de pega desse ligante avaliado por meio de ensaios de temperatura variou de $11 \mathrm{~min}$ para aproximadamente $200 \mathrm{~min}$ na presença de $0,1 \mathrm{mg} / \mathrm{m}^{2}$ de ácido cítrico [14].

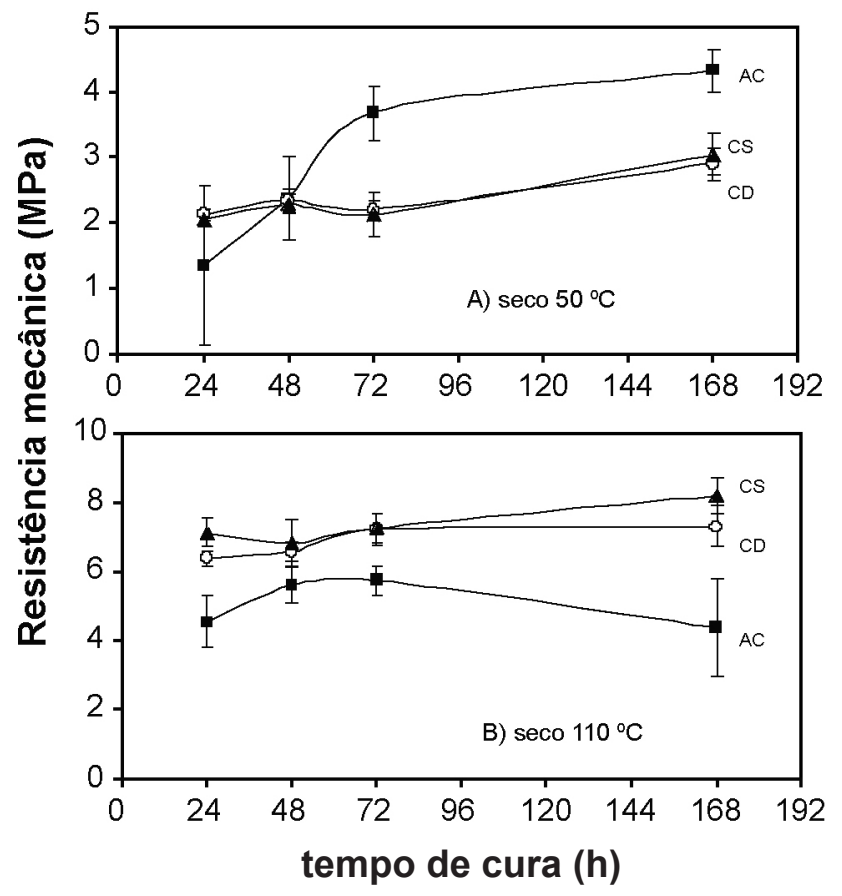

Figura 1: Resistência mecânica após secagem a 50 ou $110^{\circ} \mathrm{C}$, em função do tempo de cura para concretos contendo Alphabond 300 na presença de diferentes dispersantes.

[Figure 1: Mechanical strength (dried at 50 or $110^{\circ} \mathrm{C}$ ) as a function of curing time for castables prepared with Alphabond 300 containing different dispersants.]

Apesar disto, os resultados quanto à resistência mecânica de concretos preparados com os diferentes aditivos (Fig. 1) mostraram que após secagem a $50{ }^{\circ} \mathrm{C}$ a resistência obtida na presença de ácido cítrico supera aquela com os demais aditivos para maiores tempos de cura.

Uma vez que a cura foi realizada em ambiente aberto a $50{ }^{\circ} \mathrm{C}$, os concretos foram submetidos a secagem. Assim, quando avaliada a perda de água para amostras na presença dos diferentes aditivos (Fig. 2) pode-se observar que na

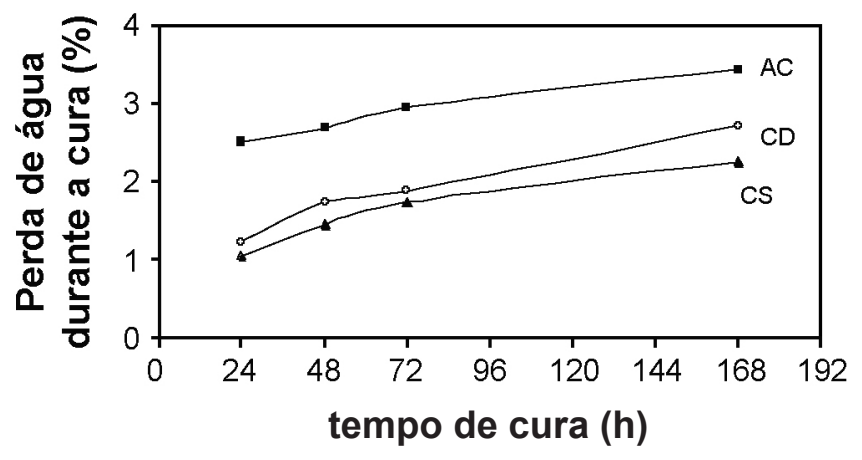

Figura 2: Perda de água em função do tempo de cura a $50{ }^{\circ} \mathrm{C}$ para concretos contendo Alphabond 300 na presença de diferentes dispersantes.

[Figure 2: Water loss as a function of the curing time at $50^{\circ} \mathrm{C}$ for castables containing Alphabond 300 in the presence of different dispersants.] 
presença de ácido cítrico o teor de água perdido aumenta com o tempo de cura. Além disso, os teores perdidos são significativamente superiores àqueles quando na presença dos demais aditivos. Esse processo de secagem pode ter contribuído para a maior resistência mecânica observada na presença de ácido cítrico.

Ainda, sendo a hidratação do ligante inibida na presença desse aditivo, um maior teor de água é eliminado durante a cura, o qual não foi consumido na formação das fases hidratadas. Entretanto, embora tenha sido observada uma vantagem com relação ao aumento de resistência mecânica, o maior teor de água livre causou o desenvolvimento de defeitos nos corpos, como ilustrado na Fig. 3. As forças de capilaridade geradas com a saída da água impulsionam a migração das partículas finas gerando vazios nos corpos.

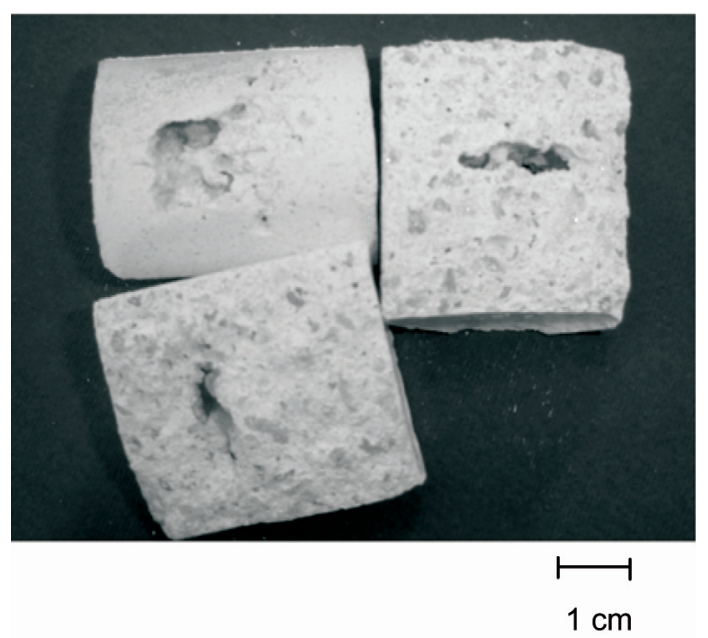

Figura 3: Concretos contendo Alphabold 300 na presença de ácido cítrico.

[Figure 3: Castables containing Alphabond 300 in the presence of citric acid.]

A presença desses defeitos aliada ao maior consumo de água envolvido na preparação do concreto na presença de ácido cítrico, podem explicar a superior porosidade obtida (Fig. 4). Isso acarretou na queda de resistência mecânica quando as amostras são avaliadas após secagem a $110{ }^{\circ} \mathrm{C}$ (Fig. 1B). Neste caso o tratamento favorece principalmente a saída de água dos corpos preparados com CD e CS, os quais não sofreram secagem prévia durante a cura. Por outro lado, nas amostras com ácido cítrico a etapa fundamental de secagem já ocorreu durante a cura a $50{ }^{\circ} \mathrm{C}$ fazendo com que a presença dos defeitos seja determinante na sua inferior resistência mecânica após secagem a $110^{\circ} \mathrm{C}$.

As curvas de secagem obtidas para os concretos preparados na presença dos diferentes dispersantes em função do tempo de cura são apresentadas na Fig. 5.

A secagem dos concretos refratários consiste na retirada da água livre e água quimicamente ligada durante a etapa de aquecimento inicial do material [15]. A "água livre" se refere àquela adicionada durante a mistura das matérias-primas

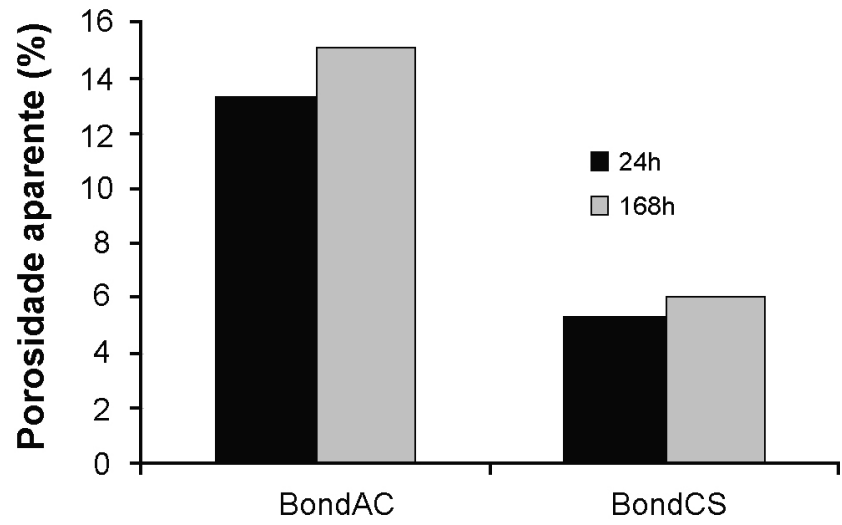

Figura 4: Porosidade aparente para concretos contendo Alphabond 300 na presença dos aditivos ácido cítrico (AC) e CS em função do tempo de cura de 24 e $168 \mathrm{~h}$ a $50{ }^{\circ} \mathrm{C}$.

[Figure 4: Apparent porosity for castables prepared with Alphabond 300 in the presence of citric acid (AC) or CS, cured at $50^{\circ} \mathrm{C}$ for 24 and $168 \mathrm{~h}$.

e que ainda permanece retida nos poros da estrutura após a etapa de cura. Já a quimicamente ligada está associada à formação de fases hidratadas devido à presença dos ligantes hidráulicos. As quantidades relativas de água livre e química dependem da quantidade de água adicionada durante a mistura do concreto, do teor e tipo de ligante e também da temperatura e tempo de cura.

A taxa de perda de massa durante a secagem é controlada, sobretudo, pela temperatura do corpo e por sua permeabilidade. Essa propriedade fluidodinâmica relacionase a quantidade e distribuição da porosidade aberta existente na microestrutura, que atua como canal para o transporte de líquidos e gases pelo corpo. Dependendo da permeabilidade pode-se aumentar a dificuldade para que o vapor de água migre do interior do corpo para a superfície.

A hidratação da alumina $\rho$ (Alphabond) envolve a formação de uma espessa camada de alumina gel e, com o decorrer da reação, parte deste gel é transformado em boemita $\left(\mathrm{Al}_{2} \mathrm{O}_{3} \cdot 1 \approx 2 \mathrm{H}_{2} \mathrm{O}=\mathrm{AH}\right)$ e principalmente baierita $\left(\mathrm{Al}_{2} \mathrm{O}_{3} \cdot 3 \mathrm{H}_{2} \mathrm{O}=\mathrm{AH}_{3}\right)$. Quando essas fases hidratadas são aquecidas ocorre a saída das hidroxilas na forma de vapor d'água cujas temperaturas correspondentes podem ser medidas por análise termogravimétrica (ensaios de secagem). A decomposição do $\mathrm{AH}_{3}$ ocorre entre 210 e $300{ }^{\circ} \mathrm{C}$, enquanto a boemita apresenta temperaturas de desidratação superiores (400-550 $\left.{ }^{\circ} \mathrm{C}\right)$ [16].

Em sintonia com o efeito retardador do processo de hidratação do ligante, na presença de ácido cítrico não são observados picos significativos relativos à formação de fases hidratadas (Fig. 5A). Apenas é verificada perda de massa significativa relativa à saída de água livre $(\sim 100$ $\left.{ }^{\circ} \mathrm{C}\right)$. Observa-se que a área desse pico varia pouco com o aumento do tempo concordando com os dados apresentados de perda de água durante a cura. Como visto, com o aumento de 24 para $168 \mathrm{~h}$ ocorreu um pequeno aumento do teor de água perdido durante a cura reduzindo a quantidade de água a ser removida durante os ensaios de secagem, justificando a 


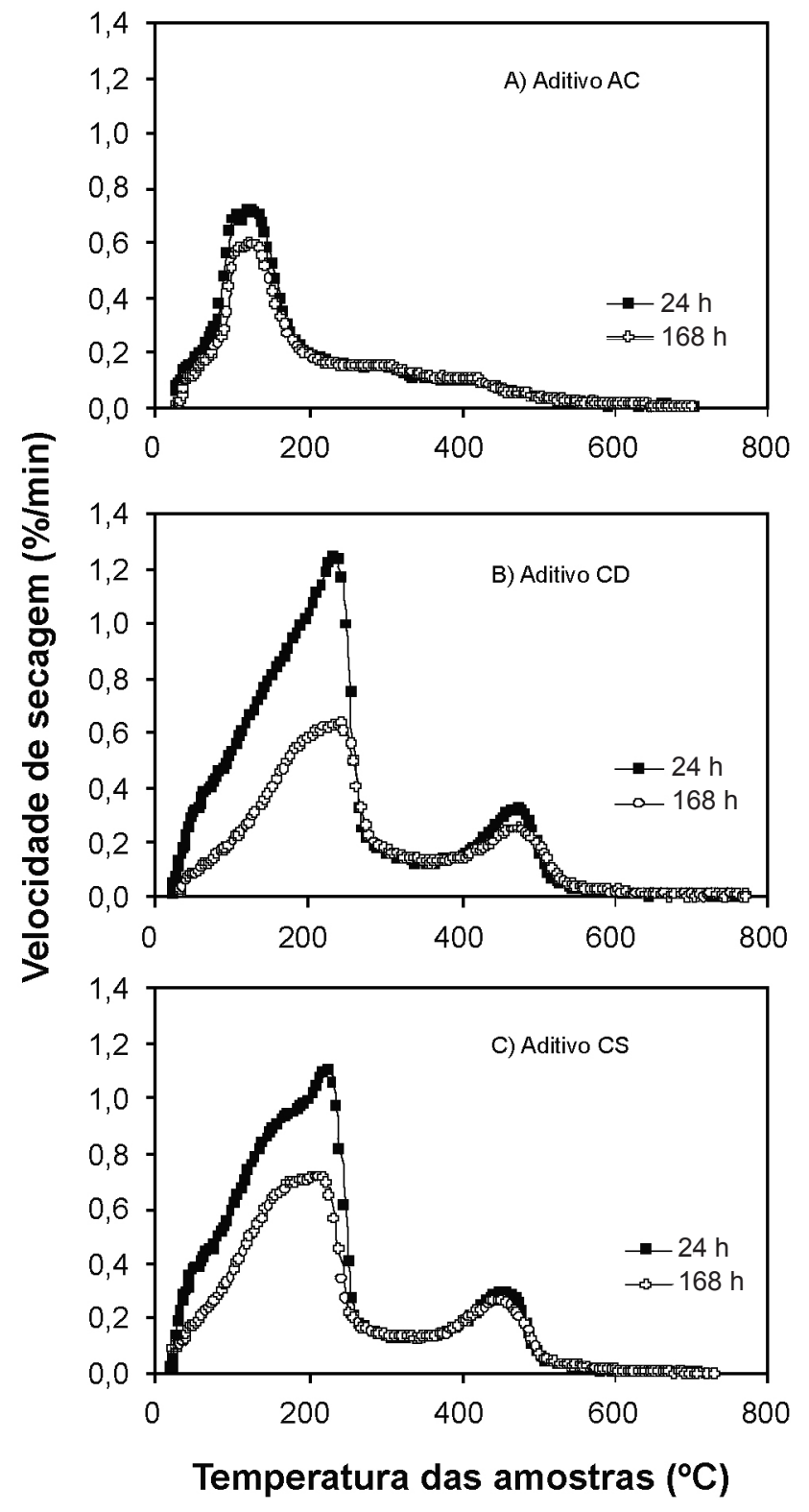

Figura 5: Velocidade de secagem em função da temperatura da amostra para concretos contendo Alphabond 300 na presença de diferentes aditivos, para os tempos de cura de $24 \mathrm{e} 168 \mathrm{~h}$ a $50{ }^{\circ} \mathrm{C}$.

[Figure 5: Drying rate as a function of the sample temperature for castables prepared with Alphabond 300 containing different additives, after curing at $50^{\circ} \mathrm{C}$ for 24 and $\left.168 \mathrm{~h}.\right]$

pequena redução do tamanho do pico próximo a $100{ }^{\circ} \mathrm{C}$.

Já na presença dos demais aditivos pode ser observada a presença de picos relativos à formação de fases hidratadas (Figs. 5 B e C). Pode-se detectar a saída de água livre e decomposição da fase $\mathrm{AH}_{3}$ abaixo de $250^{\circ} \mathrm{C}$ (primeiro pico), além da decomposição da fase $\mathrm{AH}$ acima de $400{ }^{\circ} \mathrm{C}$ (segundo pico). Cabe ressaltar que na presença desses aditivos ocorreu uma significativa redução da área do primeiro pico com o aumento do tempo de cura. Como visto, na presença dos aditivos CD e CS a água perdida após 168 h de cura é quase três vezes superior àquela perdida com apenas $24 \mathrm{~h}$ de cura (Fig. 2). Assim, quanto maior o teor de água
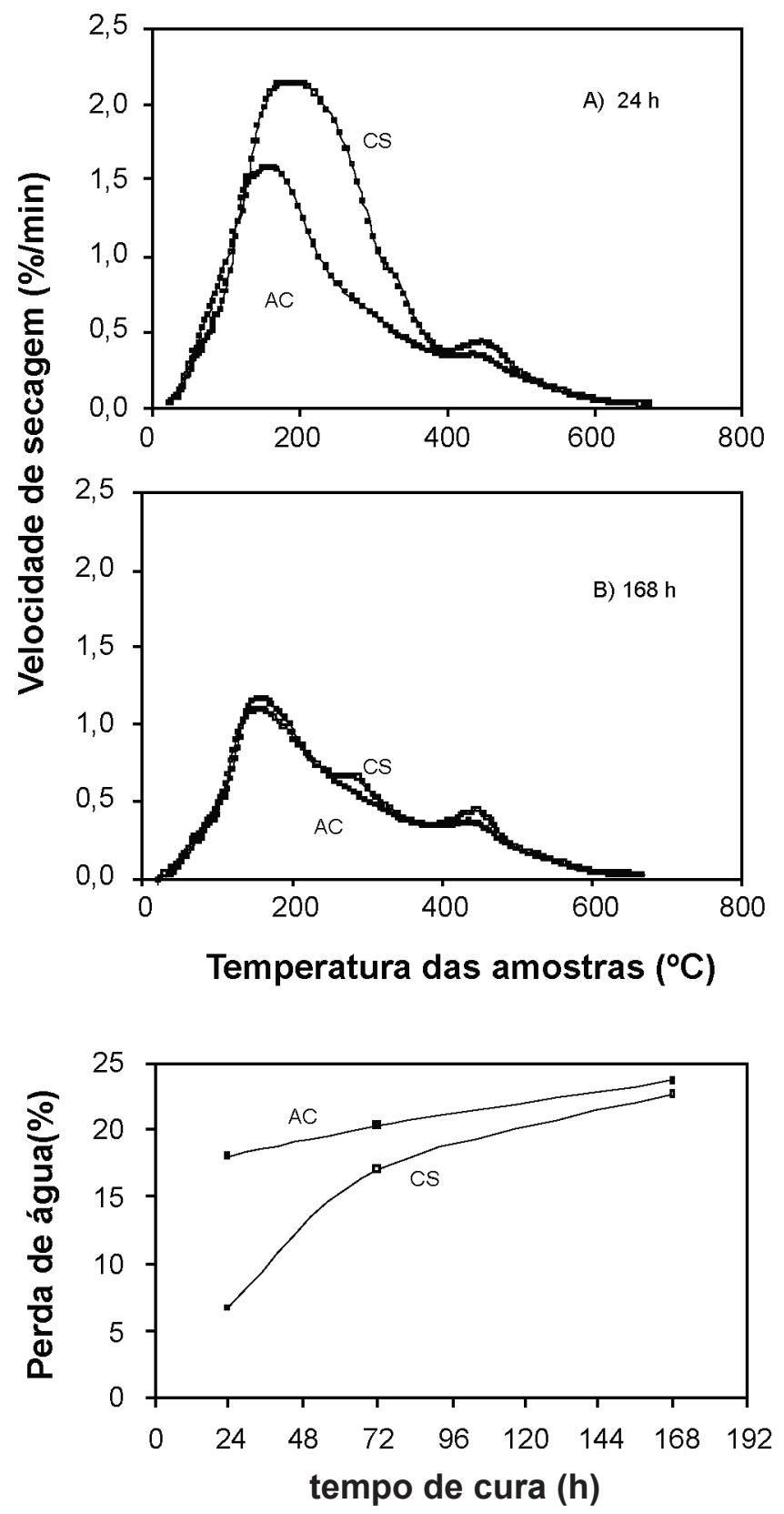

Figura 6: Velocidade de secagem em função da temperatura da amostra e perda de água em função do tempo de cura para corpos preparados a partir de suspensões aquosas de Alphabond 300 na presença dos aditivos AC e CS, curados em ambiente insaturado durante 24,72 e $168 \mathrm{~h}$.

[Figure 6: Drying rate as a function of the sample temperature and water loss as a function of the curing time for samples prepared with aqueous suspensions of Alphabond 300 containing AC and CS, after curing at $50{ }^{\circ} \mathrm{C}$ for 24,72 and $\left.168 \mathrm{~h}.\right]$

perdida durante a cura menor é a quantidade a ser eliminada durante os ensaios de secagem e, portanto menor é a área desse pico. Também a perda de água durante a cura dificulta principalmente a formação da fase $\mathrm{AH}_{3}$, sendo a formação da fase $\mathrm{AH}$ bem menos afetada resultando em áreas dos picos muito semelhantes.

A formação dessas fases a partir da hidratação do 
Tabela II - Viscosidade mínima para suspensões aquosas de Alphabond 300 (20\%-volume) na presença de um teor ótimo de dispersante.

[Table II - Viscosity measurements of suspensions containing Alphabond 300 (20 vol.\%) prepared with optimum dispersant content.]

\begin{tabular}{ccc}
\hline Tipo de dispersante & $\begin{array}{c}\text { Teor ótimo } \\
\left(\mathrm{mg} / \mathrm{m}^{2}\right)\end{array}$ & $\begin{array}{c}\text { Viscosidade } \\
\text { mínima } \\
(\mathrm{mPa} . \mathrm{s}), 50 \mathrm{~s}^{-1}\end{array}$ \\
\hline Sem dispersante & - & 154 \\
Ácido cítrico & 0,1 & 4 \\
CD & 0,3 & 6 \\
CS & 0,2 & 20 \\
\hline
\end{tabular}

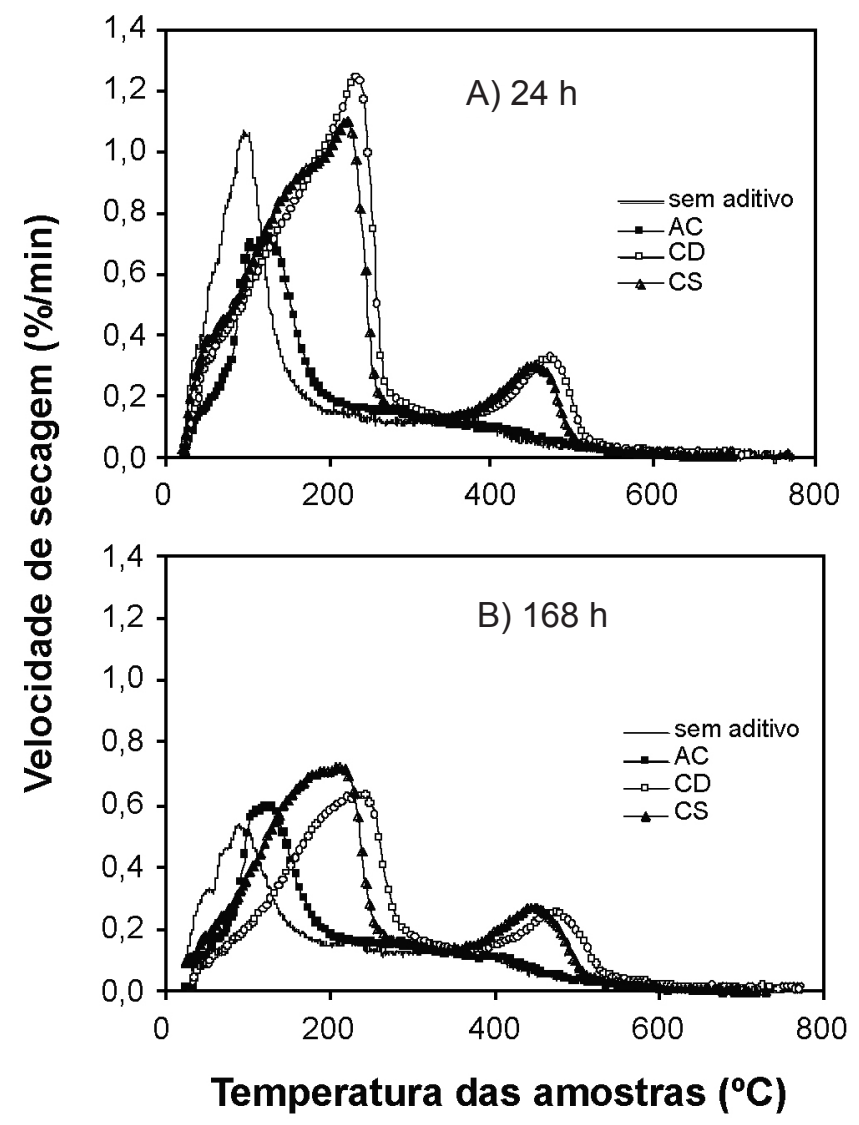

Figura 7: Velocidade de secagem em função da temperatura para concretos contendo Alphabond 300 na ausência ou na presença de diferentes aditivos, para os tempos de cura a $50{ }^{\circ} \mathrm{C}$, de 24 e $168 \mathrm{~h}$. [Figure 7: Drying rate as a function of the sample temperature for castables prepared with Alphabond 300 with or no additives, for curing at $50{ }^{\circ} \mathrm{C}$ for 24 and $\left.168 \mathrm{~h}.\right]$

ligante, bem como o efeito do teor de água perdido durante a cura, foi confirmada pelas curvas de secagem realizadas para corpos preparados a partir de suspensões aquosas de Alphabond (Fig. 6). Neste caso pode-se observar que na presença de AC a porcentagem de água perdida durante 24 $\mathrm{h}$ de cura é três vezes superior àquela perdida na presença de CS. Isso poderia explicar a significativa diferença com relação a área do primeiro pico observado na Fig. 6A. O aumento no tamanho do pico na presença de CS reflete a maior quantidade de água a ser eliminada durante o ensaio de secagem além da presença de $\mathrm{AH}_{3}$. Por outro lado, para $168 \mathrm{~h}$ de cura (Fig. 6B) a diferença com relação ao primeiro pico é quase desprezível o que pode ser correlacionado ao fato do teor de água a ser eliminado ser praticamente o mesmo na presença dos distintos aditivos (Fig. 6C).

Por fim, são apresentadas as curvas de secagem contendo ou não os diferentes dispersantes (Fig. 7). Pode-se observar que na ausência de aditivo não são observados picos relativos a hidratação do ligante, sendo verificado um pico bastante intenso referente a saída de água livre. Isso aponta para o efeito primordial da dispersão das partículas do ligante para que ocorra a hidratação. Entretanto, aditivos com cadeia curta como o ácido cítrico ao serem adsorvidos na superfície das partículas e recobrirem eficientemente a sua superfície acabam por evitar a sua hidratação. Acredita-se que aditivos que atuem sobre a dispersão, principalmente por um efeito estérico, sejam mais indicados quanto a dispersão e exposição das partículas para a hidratação. Isso poderia explicar a atuação dos aditivos CD e CS, por se tratarem de aditivos poliméricos com cadeias mais longas e na forma de pentes. Ainda, as curvas de secagem mostram que o aditivo $\mathrm{CD}$ apresenta um comportamento levemente superior ao CS quanto ao desenvolvimento de fases hidratadas. Isso pode ser atribuído ao fato desse aditivo se apresentar um pouco mais eficiente quanto a dispersão da matriz do concreto, principalmente com relação ao ligante (Tabela II), favorecendo o desenvolvimento das fases hidratadas

\section{CONCLUSÃO}

A dispersão das partículas do ligante mostra-se primordial no desenvolvimento das fases hidratadas. Entretanto, o recobrimento total das suas partículas pelo aditivo dispersante desfavorece a hidratação. Esse comportamento pode explicar a atuação do aditivo ácido cítrico o qual inibiu a hidratação do Alphabond. Isso acarreta num alto teor de água livre o qual é perdido durante a cura em ambiente aberto a $50{ }^{\circ} \mathrm{C}$. Por meio desse processo de secagem os materiais apresentam superior resistência mecânica. Entretanto, as forças de capilaridade geradas com a saída da água impulsionam a migração das partículas finas gerando defeitos nos corpos comprometendo a sua viabilidade de aplicação.

Por outro lado, os aditivos poliméricos estudados apresentam grande eficiência quanto à dispersão principalmente devido a um efeito estérico. $\mathrm{Na}$ presença desses aditivos a formação das fases $\mathrm{AH}_{3}$ e $\mathrm{AH}$ foram favorecidas. Dessa forma, podem ser apontados como eficientes para conciliar dispersão e hidratação de concretos contendo alumina hidratável como agente ligante.

\section{AGRADECIMENTOS}

à Almatis pelo fornecimento das matérias-primas. À 
FAPESP e ao CNPq pelo suporte financeiro.

\section{REFERÊNCIAS}

[1] M. D. M. Innocentini, R. G. Pileggi, F. T. Ramal Junior, V. C. Pandolfelli, "Permeability and drying behavior of PSD-designed refractory castables", Am. Ceram. Soc. Bull. 82, 7 (2003) 9401-9406.

[2] M. D. M. Innocentini, A. R. F. Pardo, V. C. Pandolfelli, "Permeability of high alumina refractory castables based on various hydraulic binders", J. Am. Ceram. Soc. 85 (2001) 1517-1521.

[3] R. Salomão, V. C. Pandolfelli, "Concretos refratários contendo fibras poliméricas: correlação entre a permeabilidade e o comportamento de secagem", Cerâmica 49, 311 (2003) 158-162.

[4] Y. Hongo, " $\rho$-Alumina bonded castable refractories", Taikabutsu Overseas 9, 1 (1989) 35-38.

[5] M. W. Vance, K. J. Moody, "Use of hydratable alumina binders in refractory compositions and related applications", Pittsburgh: Alcoa Industrial Chemicals, Internal Report (1995) 47p.

[6] W. Ma, P. W. Brown, "Mechanisms of reaction of hydratable aluminas", J. Am. Ceram. Soc. 82, 2 (1999) 453456.

[7] C. Parr, C. Wohrmeyer, B. Valdelievre, A. Namba, "Effect of formulation parameters upon the strength development of calcium aluminate cement containing castables", J. Tech. Assoc. Refract. 23, 4 (2003) 231-238.
[8] N. Bunt, C. Revais, M. Vialle, "Additives in calcium aluminate cement containing castables", in Proc. UNITECR 97 (Unified International Conference on Refractories), New Orleans, USA (1997) 1347-1354.

[9] I. R. Oliveira, A. R. Studart, R. Pileggi, V. C. Pandolfelli, "Dispersão e empacotamento de partículas - princípios e aplicações em processamento cerâmico", Fazendo Arte Editorial (2000) 195 p.

[10] R. G. Pileggi, "Ferramentas para o estudo e desenvolvimento de concretos refratários", Tese de Doutorado (2001).

[11] I. R. Oliveira, V. C. Pandolfelli, "Reologia de concretos refratários na presença de diferentes tipos de aditivo e ligante hidráulico", Cerâmica 53, 327 (2007) 263-269.

[12] R. G. Pileggi, V. C. Pandolfelli, A. E. Paiva, J. Gallo, "Novel rheometer for refractory castables", Am. Ceram. Soc. Bull. 79, 1 (2000) 54-58.

[13] R. G. Pileggi, A. R. Studart, V. C. Pandolfelli, "How mixing affects the rheology of refractory castables Part I", Am. Ceram. Soc. Bull. 80, 6 (2001) 27-31 .

[14] I. R. Oliveira, V. C. Pandolfelli, "Hidratação de ligantes na presença de matriz e aditivos", Cerâmica 53, 327 (2007) 240-248.

[15] G. W. Scherer, “Theory of drying”, J. Am. Ceram. Soc. 73, 1 (1990) 3-14.

[16] T. D. Robson, "Aluminous Cement in refractory castables", Chemistry Cements, vol. 2, Academic Press (1964).

(Rec. 19/02/2008, Ac. 04/04/2008) 